\title{
MÉTODOS QUANTITATIVOS PARA AVALIAÇÃO DA FORÇA DE LÍNGUA
}

\section{Quantitative methods for assessing tongue force}

\author{
Renata Maria Moreira Moraes Furlan (1), Amanda Freitas Valentim (2), Andréa Rodrigues Motta ${ }^{(3)}$, \\ Márcio Falcão Santos Barroso ${ }^{(4)}$, Cláudio Gomes da Costa ${ }^{(5)}$, Estevam Barbosa de Las Casas ${ }^{(6)}$
}

\begin{abstract}
RESUMO
Por muitos anos, pesquisadores têm procurado métodos para quantificar a força da língua e muitos instrumentos foram construídos para este fim. O objetivo deste trabalho é apresentar uma revisão crítica da literatura sobre instrumentos para quantificar a força de língua. Os 30 aparelhos encontrados foram agrupados em quatro diferentes categorias: bocal contendo sensores $(n=9)$, sensores fixados nos dentes, palato ou em placas palatais $(n=8)$, bulbos preenchidos com fluidos e conectados a sensores de pressão $(n=7)$ e outras tecnologias $(n=8)$. Esses instrumentos podem, potencialmente, auxiliar o fonoaudiólogo na avaliação miofuncional orofacial, fazendo com que o diagnóstico de força da língua seja mais preciso. Alguns aparelhos apresentam desvantagens, tais como não serem sensíveis a pequenas mudanças de força, dificuldades na reprodutibilidade do posicionamento e outros pontos específicos. A grande variação de valores de força/pressão máxima e média encontrados relaciona-se à grande diversidade dos métodos, que empregam diferentes tecnologias.
\end{abstract}

DESCRITORES: Língua; Força Muscular; Avaliação

(1) Fonoaudióloga; Doutoranda em Engenharia Biomecânica pelo Departamento de Engenharia de Estruturas da Universidade Federal de Minas Gerais - UFMG, Belo Horizonte, Minas Gerais, Brasil; Mestre em Bioengenharia pelo Departamento de Engenharia Mecânica da Universidade Federal de Minas Gerais.

(2) Fonoaudióloga; Mestranda em Bioengenharia pelo Programa de Pós Graduação em Engenharia Mecânica da Universidade Federal de Minas Gerais - UFMG, Belo Horizonte, Minas Gerais, Brasil.

(3) Fonoaudióloga; Professora Adjunto do Departamento de Fonoaudiologia da Universidade Federal de Minas Gerais UFMG, Belo Horizonte, Minas Gerais, Brasil; Doutora em Distúrbios da Comunicação Humana pela Universidade Federal de São Paulo.

(4) Engenheiro; Professor Adjunto do Departamento de Engenharia Elétrica da Universidade Federal de São João del-Rei - UFSJ, São João del-Rei, Minas Gerais, Brasil; Doutor em Engenharia Elétrica pela Universidade Federal de Minas Gerais.

(5) Engenheiro; Pesquisador em Ciência e Tecnologia da Fundação Centro Tecnológico de Minas Gerais - CETEC, Belo Horizonte, Minas Gerais, Brasil; Mestre em Engenharia Mecânica pela Universidade Federal de Minas Gerais.

(6) Engenheiro; Professor Titular do Departamento de Engenharia de Estruturas da Universidade Federal de Minas Gerais - UFMG, Belo Horizonte, Minas Gerais, Brasil; Doutor em Engenharia de Estruturas pela Purdue University, EUA.

Conflito de interesses: inexistente

\section{INTRODUÇÃO}

Durante muitos anos, pesquisadores têm procurado métodos para quantificar a força ou pressão exercida pela língua. Uma força adequada é essencial para que a língua possa desempenhar corretamente as funções de mastigação, deglutição, sucção, respiração e articulação da fala, além de manter os dentes em posição adequada, já que a força exercida pela língua nos dentes se equilibra com as forças exercidas por lábios e bochechas ${ }^{1}$.

A força de língua pode ser avaliada por métodos qualitativos ou quantitativos. A avaliação qualitativa é mais utilizada na prática clínica dos fonoaudiólogos. Este tipo de avaliação depende da experiência do profissional e apresenta controvérsias. Neste procedimento, o tônus/tensão da língua é geralmente testado solicitando-se que o paciente protrua a língua contra o dedo enluvado do avaliador, ou contra uma espátula, enquanto o fonoaudiólogo mantém uma resistência ${ }^{2}$. Já a avaliação quantitativa é realizada utilizando instrumentos que mostram o valor de força exercido pelo sujeito, o que permite que o diagnóstico de força da língua seja mais preciso. 
Sendo assim, o objetivo deste trabalho é apresentar uma revisão crítica da literatura sobre os instrumentos para quantificar a força da língua.

\section{MÉTODO}

Realizou-se revisão crítica da literatura sobre os instrumentos para quantificar força de língua em bibliotecas e bases de dados como Medline, Lilacs e banco de patentes. Foram considerados os artigos escritos em português e inglês, publicados entre 1980 e 2011. Os termos utilizados na pesquisa foram "língua", "força", "pressão", ou em inglês "tongue", "force", "strength", "pressure". Foi realizada uma pesquisa adicional nas referências bibliográficas dos artigos selecionados.

A análise do material foi realizada em três etapas: na primeira, os artigos que não contemplavam os objetivos estabelecidos foram excluídos; na segunda, as referências duplicadas nas bases de dados consultadas foram eliminadas; e, na terceira, os trabalhos que descreviam o mesmo instrumento foram excluídos.
Foram localizadas, inicialmente, 93 referências, sendo que após a terceira fase, permaneceram no presente estudo 32 trabalhos. Realizou-se uma breve descrição de cada artigo, contendo informações como amostra, métodos e resultados obtidos, sendo apresentados apenas os resultados de indivíduos saudáveis. Para documentos de patente, foram descritos somente o instrumento e a metodologia.

\section{REVISÃO DA LITERATURA}

Diversos métodos para quantificar a força/ pressão da língua foram encontrados. Os instrumentos foram agrupados em quatro categorias, de acordo com a tecnologia utilizada: bocal contendo sensores $(n=9)$ apresentados na Figura 1; sensores fixados nos dentes, palato ou em placas palatais $(n=8)$ que se encontram na Figura 2; bulbos preenchidos com fluidos e conectados a sensores de pressão $(n=7)$ demonstrados na Figura 3 e outras tecnologias $(n=8)$ que são apresentadas na Figura 4.

\begin{tabular}{|c|c|c|c|}
\hline $\begin{array}{l}\text { TECNOLOGIA/ } \\
\text { REFERÊNCIA }\end{array}$ & MÉTODO PROPOSTO & AMOSTRA & RESULTADOS \\
\hline Dworkin et al.,1980 ${ }^{3}$ & $\begin{array}{l}\text { Extensômetro soldado em uma haste tubular e gravador portátil } \\
\text { de um canal. O transdutor de força podia ser posicionado } \\
\text { anteriormente, entre os incisivos superiores e inferiores ou } \\
\text { lateralmente, entre o canino e primeiro pré-molar. O sujeito era } \\
\text { solicitado a morder a haste e aplicar força com o ápice lingual } \\
\text { contra o transdutor. }\end{array}$ & $\begin{array}{l}67 \text { homens e } 58 \\
\text { mulheres com } \\
\text { idades entre } 20 \\
\text { e } 72 \text { anos. }\end{array}$ & $\begin{array}{c}\text { Força máxima medida } \\
\text { anteriormente: } 32,9 \mathrm{~N} \\
\text { em homens e } 27,5 \mathrm{~N} \\
\text { em mulheres. Força } \\
\text { máxima à direita: } 31,7 \\
\mathrm{~N} \text { em homens e } 28,7 \\
\mathrm{~N} \text { em mulheres. Força } \\
\text { máxima à esquerda: } \\
29,3 \mathrm{~N} \text { em homens e } \\
23,7 \mathrm{~N} \text { em mulheres. }\end{array}$ \\
\hline Durkee, $1987^{4}$ & $\begin{array}{l}\text { Aparelho contido dentro de um recipiente cilíndrico aberto na } \\
\text { região anterior de onde partia uma estrutura tubular, com uma } \\
\text { placa dentária individual, de material de impressão dentária, } \\
\text { para o posicionamento dos dentes. Uma haste percorria o } \\
\text { aparelho em toda sua extensão. Na extremidade anterior dessa } \\
\text { haste, havia um receptáculo para a língua, e na sua extremidade } \\
\text { posterior, a haste ligava-se a um diafragma posicionado próximo } \\
\text { à parede interna posterior do aparelho. Para detecção e medição } \\
\text { das forças nas direções horizontal e vertical, dois extensômetros } \\
\text { foram montados sobre a haste, posicionados a } 90^{\circ} \text {, um em } \\
\text { relação ao outro. Quando a haste deslocava-se nestas direções, } \\
\text { estes sensores eram pressionados na própria parede do } \\
\text { aparelho. Um terceiro extensômetro encontrava-se em contato } \\
\text { com o diafragma, detectava a força da língua na direção anterior. } \\
\text { Os sinais provenientes dos extensômetros eram direcionados } \\
\text { para um circuito de amplificação e, depois, para um osciloscópio } \\
\text { ou uma tela de computador. }\end{array}$ & $\mathbf{x}$ & $\mathbf{x}$ \\
\hline
\end{tabular}




\begin{tabular}{|c|c|c|c|}
\hline $\begin{array}{l}\text { TECNOLOGIA/ } \\
\text { REFERÊNCIA }\end{array}$ & MÉTODO PROPOSTO & AMOSTRA & RESULTADOS \\
\hline $\begin{array}{l}\text { Robinovitch et al., } \\
1991^{5}\end{array}$ & $\begin{array}{l}\text { O instrumento, denominado TOMS, consistia em uma viga de } \\
\text { alumínio com uma das extremidades livre onde se encaixavam } \\
\text { dois extensômetros em lados opostos na base da viga, } \\
\text { organizados com dois resistores passivos, em configuração } \\
\text { de ponte de Wheatstone. Este era capaz de medir a força da } \\
\text { língua no sentido vertical e, quando a viga era rotacionada em } \\
90^{\circ} \text {, podia-se medir no sentido lateral direito e esquerdo. O } \\
\text { transdutor era revestido por um bocal de polipropileno, moldado } \\
\text { individualmente a fim de acomodar as arcadas dentárias de cada } \\
\text { indivíduo, e permitia uma abertura de boca de aproximadamente } \\
40 \% \text { do limite máximo. A língua entrava em contato apenas } \\
\text { com o transdutor. O sinal gerado era amplificado e transmitido } \\
\text { a um conversor analógico-digital. Uma superfície côncava de } \\
\text { borracha foi colocada ao final da viga para acomodar a língua. }\end{array}$ & $\begin{array}{l}\text { A amostra foi } \\
\text { composta por } \\
6 \text { indivíduos } \\
\text { normais com } \\
\text { idades entre } \\
22 \text { e } 34 \text { anos, } \\
\text { sendo } 5 \text { homens } \\
\text { e } 1 \text { mulher. } \\
\text { Entretanto foram } \\
\text { apresentados } \\
\text { apenas os } \\
\text { valores de um } \\
\text { indivíduo. }\end{array}$ & $\begin{array}{l}\text { Força máxima lateral } \\
\text { de um indivíduo: } 14,1 \\
\mathrm{~N} \text {. Média da força } \\
\text { lateral: } 3,0 \mathrm{~N} \text {. }\end{array}$ \\
\hline $\begin{array}{c}\text { Scardella et al., } \\
1993^{6}\end{array}$ & $\begin{array}{l}\text { Transdutor de força que transfere as forças de compressão } \\
\text { direta geradas pela língua para um braço ativo fora da cavidade } \\
\text { oral, conectado a um extensômetro com resposta linear para } \\
\text { forças entre } 50 \text { e } 100 \text { gf, que foi incorporado a um circuito de } \\
\text { ponte de dois braços ativos. }\end{array}$ & $\begin{array}{l}\text { Cinco homens } \\
\text { com idades } \\
\text { entre } 21 \text { e } 36 \\
\text { anos. }\end{array}$ & $\begin{array}{l}\text { A força máxima } \\
\text { variou de } 9,50 \text { a } \\
16,33 \mathrm{~N} \text {. A média da } \\
\text { força máxima foi de } \\
12,67 \pm 1,25 \mathrm{~N} \text {. }\end{array}$ \\
\hline Blumen et al., $2002^{7}$ & $\begin{array}{l}\text { Bocal plástico em forma de } U \text { constituído de material de molde } \\
\text { dentário para fixar o instrumento aos dentes inferiores. Um } \\
\text { braço de contato apresentava pequeno desnível para indicar } \\
\text { onde posicionar a língua e era conectado a um extensômetro } \\
\text { localizado fora da boca e conectado a amplificadores. Os sinais } \\
\text { de resposta eram lineares de } 0,49 \text { a } 9,81 \mathrm{~N} \text { e eram gravados em } \\
\text { um microcomputador por meio de um sistema analógico-digital. }\end{array}$ & $\begin{array}{l}\text { Oito homens } \\
\text { com idades } \\
\text { entre } 25 \text { e } 50 \\
\text { anos. }\end{array}$ & $\begin{array}{c}\text { Força máxima: } \\
5,44 \pm 1,52 \mathrm{~N} \text {. }\end{array}$ \\
\hline $\begin{array}{c}\text { Mortimore et al., } \\
1999^{8}\end{array}$ & \begin{tabular}{|l|} 
Transdutor de força composto por uma alça de nylon e um bocal. \\
O bocal consistia de uma placa de nylon de $1 \mathrm{~cm}$ de diâmetro \\
atrás da qual encontrava-se uma célula de carga com capacidade \\
de $0 \pm 6 \mathrm{Kg}$. Atrás da placa, havia um sulco de aproximadamente \\
$2 \mathrm{~mm}$ de profundidade e $2 \mathrm{~mm}$ de largura onde os indivíduos \\
posicionavam os incisivos superiores e inferiores a fim de manter \\
o aparelho fixo na boca. O transdutor foi conectado a uma escala \\
linear visual que mostrava o valor da força em newton ou a \\
porcentagem da força em relação ao valor máximo do indivíduo.
\end{tabular} & $\begin{array}{c}81 \text { homens e } 86 \\
\text { mulheres com } \\
\text { idades entre } 42 \\
\text { e } 62 \text { anos. }\end{array}$ & $\begin{array}{c}\text { A força máxima obtida } \\
\text { foi de } 26 \pm 8 \mathrm{~N} \text { para os } \\
\text { homens e } 20 \pm 7 \mathrm{~N} \text { para } \\
\text { as mulheres. }\end{array}$ \\
\hline Miller et al., $2008^{9}$ & $\begin{array}{l}\text { Uma placa de metal coberta por um elemento descartável e } \\
\text { fixada em uma haste de comprimento regulável que fazia o } \\
\text { acoplamento da placa com um extensômetro. Este conjunto } \\
\text { placa-haste-sensor, encontrava-se fixado em um disco } \\
\text { posicionado verticalmente, ao qual podiam ser fixados outros } \\
\text { sensores, e, o disco, ao ser girado, modificava a direção de } \\
\text { posicionamento da placa e o sentido da força necessária para } \\
\text { empurrá-la possibilitando assim a medição da força da língua nas } \\
\text { múltiplas direções e sentidos. O suporte do aparelho abrigava o } \\
\text { transdutor e o sistema eletrônico. O sinal gerado pelo transdutor } \\
\text { era processado eletronicamente para a produção de um sinal de } \\
\text { saída que era o perfil da amplitude da força exercida pela língua } \\
\text { ao longo do tempo. Durante a medição o paciente encontrava-se } \\
\text { posicionado de frente para o aparelho com o queixo sobre um } \\
\text { suporte, devendo exercer força com a língua sobre o elemento } \\
\text { receptor da força, a placa. }\end{array}$ & $\mathbf{x}$ & $\mathbf{x}$ \\
\hline$\underset{10}{\text { Sangave et al. } 2008}$ & $\begin{array}{l}\text { Instrumento que consistia de dois bocais, um superior e um } \\
\text { inferior, com três sensores de força em cada. Os sensores eram } \\
\text { do tipo piezoresistivos, Flexiforce A201, da marca Tekscan, com } \\
\text { faixa de medição de } 0 \text { a } 110 \mathrm{~N} \text { e estavam distribuídos de forma } \\
\text { a medir a força da língua na direção horizontal, nos sentido para } \\
\text { frente, para direita e para esquerda. Cada sensor encontrava-se } \\
\text { fixado sobre uma placa de aço inoxidável presa no bocal. Sobre o } \\
\text { sensor havia uma peça de silicone constituída de duas camadas } \\
\text { de } 1,58 \mathrm{~mm} \text { cada, porém com áreas diferentes, a maior (13 mm } \\
\text { x } 8 \mathrm{~mm} \text { ) ficava em contato com a língua sendo pressionada por } \\
\text { ela durante as medições e a menor ( } \mathrm{mm} \text { x } 8 \mathrm{~mm} \text { ) em contato } \\
\text { com o sensor e dessa forma maximizava-se a transferência } \\
\text { da força da área maior para a menor. O sistema possuía uma } \\
\text { interface gráfica construída em Labview que mostrava a força } \\
\text { exercida pela língua em cada sensor separadamente permitindo } \\
\text { compará-la com dados coletados previamente. }\end{array}$ & $\mathbf{x}$ & $\mathbf{x}$ \\
\hline
\end{tabular}




\begin{tabular}{|c|c|c|c|}
\hline $\begin{array}{l}\text { TECNOLOGIA/ } \\
\text { REFERÊNCIA }\end{array}$ & MÉTODO PROPOSTO & AMOSTRA & RESULTADOS \\
\hline Furlan, $2011^{11}$ & $\begin{array}{l}\text { Bocal de material termoplástico no interior do qual se encaixa } \\
\text { uma peça base sobre a qual está apoiado um sensor de força } \\
\text { Flexiforce A201, da marca Tekscan, com faixa de medição de } 0 \\
\text { a } 110 \mathrm{~N} \text {. Uma peça guia encaixa-se na base e tem a função de } \\
\text { prender o sensor à base e servir de guia para a peça aplicadora } \\
\text { de força. A peça aplicadora consiste de um disco que fica em } \\
\text { contato com a língua do usuário e um pino que pressiona o } \\
\text { sensor durante a aplicação de força pela língua no disco. Era } \\
\text { solicitado aos indivíduos que impulsionassem o êmbolo com a } \\
\text { maior força de que fossem capazes de realizar e manter por } 10 \\
\text { segundos. O procedimento foi realizado por mais duas vezes } \\
\text { com intervalos de um minuto de descanso entre as medicões. }\end{array}$ & $\begin{array}{l}20 \text { indivíduos } \\
\text { saudáveis, } \\
\text { sendo } 10 \\
\text { homens e } 10 \\
\text { mulheres com } \\
\text { idades entre } 20 \\
\text { e } 33 \text { anos. }\end{array}$ & $\begin{array}{c}\text { Força média: } 19,4 \mathrm{~N} \\
\text { para o sexo masculino } \\
\text { e } 13,8 \mathrm{~N} \text { para o sexo } \\
\text { feminino. } \\
\text { Força máxima: } 24,9 \mathrm{~N} \\
\text { para o sexo masculino } \\
\text { e } 18,0 \mathrm{~N} \text { para o sexo } \\
\text { feminino. }\end{array}$ \\
\hline
\end{tabular}

Legenda: $\mathrm{x}=$ dados de patente

Figura 1 - Dispositivos que empregam bocais contendo sensores

\begin{tabular}{|c|c|c|c|}
\hline $\begin{array}{l}\text { TECNOLOGIA/ } \\
\text { REFERÊNCIA }\end{array}$ & MÉTODO PROPOSTO & AMOSTRA & RESULTADOS \\
\hline $\begin{array}{c}\text { Staehlin et al., } \\
1999^{12}\end{array}$ & $\begin{array}{l}\text { Placa palatal equipada com um ou mais sensores de pressão para } \\
\text { medir a pressão exercida pela língua durante a função. Quando os } \\
\text { sensores eram tocados pela língua, produziam um sinal elétrico } \\
\text { proporcional à pressão aplicada. O sinal elétrico era conduzido a } \\
\text { um dispositivo de controle e visualização, que fornecia um feedback } \\
\text { visual ao sujeito avaliado. }\end{array}$ & $x$ & $x$ \\
\hline $\begin{array}{l}\text { Wakumoto et al., } \\
2003^{13}\end{array}$ & $\begin{array}{l}\text { Placa palatal de resina termoplástica moldada para cada indivíduo } \\
\text { com } 10 \text { sensores resistivos de } 0,1 \mathrm{~mm} \text { de espessura e } 3 \mathrm{~mm} \text { de } \\
\text { diâmetro, dispostos em três filas, na superfície inferior da placa. Os } \\
\text { sensores estavam conectados a um sistema externo por meio de } \\
\text { fios que passavam atrás do terceiro molar e saíam da cavidade oral } \\
\text { através do vestíbulo ligando-se a um computador. }\end{array}$ & $\mathrm{x}$ & $x$ \\
\hline $\begin{array}{c}\text { Robbins et al., } \\
2004^{14}\end{array}$ & $\begin{array}{l}\text { Suporte adjacente ao palato duro moldado em acrílico dentário com } \\
\text { formato anatômico e com dois sensores de pressão do tipo resistivo } \\
\text { na superfície inferior do suporte dispostos ao longo de um plano } \\
\text { médio sagital de modo a fornecer dois pontos para medição da } \\
\text { pressão, um próximo a região alveolar e outro próximo ao centro do } \\
\text { palato. Um bocal duplo em formato de C com o suporte do sensor } \\
\text { anexado em um ponto central da placa apoiava-se nos dentes } \\
\text { do paciente e tinha a finalidade de tornar reprodutível a posição } \\
\text { dos sensores na cavidade oral. Além disso, adaptava-se a uma } \\
\text { variedade de arcadas dentárias já que era moldável pelo calor. O } \\
\text { aparelho permitia ao paciente fechar a boca de maneira semelhante } \\
\text { ao que acontece durante a deglutição normal. Além disso, fornecia } \\
\text { feedback visual por meio de uma lâmpada, um gerador de tom e um } \\
\text { display digital que mostrava informações sobre os picos de pressão, } \\
\text { a pressão média ou a porcentagem em relação a um pico de pressão } \\
\text { predeterminado. }\end{array}$ & $x$ & $x$ \\
\hline $\begin{array}{l}\text { Ruan et al., } \\
2005^{15}\end{array}$ & $\begin{array}{l}\text { Um aparelho composto por um extensômetro auxiliado por } \\
\text { computador com transdutor de espessura } 0,7 \mathrm{~mm} \text {. O transdutor foi } \\
\text { cimentado com adesivo de esmalte de marca chinesa em } 6 \text { posições } \\
\text { diferentes: na superfície labial e lingual do incisivo central superior, } \\
\text { idem para incisivo central inferior, superfície bucal e lingual do molar } \\
\text { superior e o mesmo para molar inferior. Primeiramente foi realizada } \\
\text { medição no repouso e depois em deglutição de } 3 \mathrm{~mL} \text { de água, sendo } \\
\text { este procedimento repetido três vezes para cada posição. }\end{array}$ & $\begin{array}{c}19 \text { meninos } \\
\text { e dezenove } \\
19 \text { de } 3 \text { a } 6 \\
\text { anos de idade, } \\
\text { com dentição } \\
\text { decídua } \\
\text { completa e } \\
\text { oclusão normal. }\end{array}$ & $\begin{array}{l}\text { As medianas das } \\
\text { forças linguais no } \\
\text { repouso foram de } 37 \mathrm{~N} / \\
\mathrm{m}^{2} \text { no incisivo e } 20,5 \mathrm{~N} / \\
\mathrm{m}^{2} \text { no molar, enquanto } \\
\text { em deglutição foram de } \\
1679 \mathrm{~N} / \mathrm{m}^{2} \text { e } 2228,5 \mathrm{~N} / \\
\mathrm{m}^{2} \text { respectivamente } \\
\end{array}$ \\
\hline Hori et al., 2006 & $\begin{array}{l}\text { Instrumento que objetivava medir a pressão de língua durante a } \\
\text { mastigação e a deglutição utilizando sete sensores de pressão, com } \\
\text { capacidade para medir até } 200 \mathrm{kPa} \text {, instalados em uma placa palatal } \\
\text { e gravados em um computador por meio de uma placa de interface. } \\
\text { Cada sensor foi fixado em um disco de liga de ouro, prata e paládio } \\
\text { para evitar que o efeito da deformação na resina aparecesse nos } \\
\text { dados experimentais. Os cabos de cada sensor foram passados por } \\
\text { um tubo de vinil ( } 1 \mathrm{~mm} \text { de diâmetro) para sair da cavidade oral pelo } \\
\text { vestíbulo oral. }\end{array}$ & $\begin{array}{l}\text { Dez sujeitos } \\
\text { entre } 24 \text { e } 30 \\
\text { anos, sendo } \\
\text { oito homens e } \\
\text { duas mulheres. }\end{array}$ & $\begin{array}{c}\text { A pressão medida } \\
\text { durante a deglutição } \\
\text { variou entre } 0,8 \text { e } 17,1 \\
\text { kPa. }\end{array}$ \\
\hline
\end{tabular}




\begin{tabular}{|c|c|c|c|}
\hline $\begin{array}{l}\text { TECNOLOGIA/ } \\
\text { REFERÊNCIA }\end{array}$ & MÉTODO PROPOSTO & AMOSTRA & RESULTADOS \\
\hline $\begin{array}{c}\text { Hewitt et al., } \\
2008{ }^{17}\end{array}$ & $\begin{array}{l}\text { O Madison Oral Strengthening Therapeutic (MOST) consistia em } \\
\text { um bocal polimérico, do tipo utilizado por atletas adultos, no qual } \\
\text { uma placa palatal feita de resina dentária e contendo um sensor de } \\
\text { força, foi fixada. As leituras de pressão foram obtidas conectando-se } \\
\text { o bocal do MOST a um circuito eletrônico simples. A tensão elétrica } \\
\text { foi gravada com frequência de } 500 \mathrm{~Hz} \text { diretamente a um arquivo } \\
\text { eletrônico de texto, utilizando cartões de aquisição e o software } \\
\text { LabVIEW. }\end{array}$ & $\begin{array}{l}36 \text { sujeitos } \\
\text { entre } 19 \text { e } 71 \\
\text { anos, sendo } 18 \\
\text { homens e } 18 \\
\text { mulheres. }\end{array}$ & * \\
\hline $\begin{array}{l}\text { Kieser et al., } \\
2008^{18}\end{array}$ & $\begin{array}{l}\text { Uma placa palatal foi projetada para fornecer medidas simultâneas } \\
\text { de pressão em diversos locais da cavidade oral tendo sido } \\
\text { construída com uma liga de cromo e cobalto. Para medir a pressão } \\
\text { durante a deglutição, um par anterior de sensores media o contato } \\
\text { labial e lingual contra o dente incisivo central esquerdo; dois pares } \\
\text { de sensores mediam as contribuições da margem lateral da língua } \\
\text { e bochechas no canino e primeiro molar. Finalmente, a pressão da } \\
\text { língua na linha média do palato foi medida por dois sensores, um } \\
\text { na linha dos pré-molares e outro no limite posterior do palato duro. } \\
\text { A saída dos oito canais foi recolhida simultaneamente por meio } \\
\text { de um amplificador de ponte para oito canais e então foi gravada } \\
\text { e mostrada em um computador. Registrou-se a pressão intraoral } \\
\text { durante a deglutição de } 10 \mathrm{~mL} \text { de água. }\end{array}$ & $\begin{array}{l}\text { Cinco sujeitos } \\
\text { adultos, três } \\
\text { homens e duas } \\
\text { mulheres, com } \\
\text { idades entre } 25 \\
\quad \text { e } 27 \text { anos. }\end{array}$ & $\begin{array}{c}\text { As pressões obtidas } \\
\text { variaram de } 13,05 \mathrm{a} \\
289,75 \mathrm{kPa} .\end{array}$ \\
\hline Hori et al., 2009 & $\begin{array}{l}\text { Modificação do instrumento apresentado por Hori et al., 2006, } \\
\text { utilizando somente cinco sensores, três posicionados ao longo da } \\
\text { linha média e dois na parte lateral-posterior do palato duro. Não } \\
\text { foram utilizadas placas palatais. Os sensores foram fixados ao } \\
\text { palato utilizando uma resina adesiva. }\end{array}$ & $\begin{array}{l}30 \text { sujeitos, } \\
\text { sendo } 20 \\
\text { homens e } 10 \\
\text { mulheres com } \\
\text { idades entre } 24 \\
\text { e } 35 \text { anos, }\end{array}$ & $\begin{array}{c}\text { A pressão obtida } \\
\text { durante a deglutição } \\
\text { variou entre } 1,0 \text { e } 14,5 \\
\mathrm{kPa}\end{array}$ \\
\hline
\end{tabular}

Legenda: $\mathrm{x}=$ dados de patente,${ }^{*}=$ dados não disponíveis

Figura 2 - Dispositivos que empregam sensores fixados nos dentes, no palato ou em placas palatais

\begin{tabular}{|c|c|c|c|}
\hline $\begin{array}{l}\text { TECNOLOGIA/ } \\
\text { REFERÊNCIA }\end{array}$ & MÉTODO PROPOSTO & AMOSTRA & RESULTADOS \\
\hline $\begin{array}{c}\text { Robin et al., } \\
1992^{20}\end{array}$ & $\begin{array}{l}\text { Aparelho portátil detector de pressão que empregava um bulbo } \\
\text { preenchido por água de um tamanho adequado para caber na } \\
\text { cavidade oral. O bulbo era conectado a um transdutor para converter } \\
\text { a pressão detectada em sinal elétrico. O bulbo era resiliente para } \\
\text { deformar quando submetido à pressão gerada pela língua e retornar } \\
\text { à forma inicial quando a pressão fosse removida. Um monitor de } \\
\text { saída mostrava a pressão exercida. }\end{array}$ & $x$ & $x$ \\
\hline $\begin{array}{l}\text { Bu Sha et al., } \\
\qquad 2000^{21}\end{array}$ & $\begin{array}{l}\text { Um tubo de poli cloreto de vinila (PVC) de } 10 \mathrm{~cm} \text { de comprimento } \\
\text { e } 1,9 \mathrm{~cm} \text { de diâmetro contendo um balão de látex de catéter fixado } \\
\text { por material de impressão dentária no tubo. Quando inflado com } 4 \\
\mathrm{~mL} \text { de solução de cloreto de sódio e água, o balão ultrapassava em } \\
1,0 \mathrm{~cm} \text { a extremidade final do tubo. Esta extremidade foi revestida } \\
\text { com borracha para que o sujeito tivesse uma superfície macia para } \\
\text { morder enquanto fazia a força de protrusão com a língua. O catéter } \\
\text { conectava-se a um transdutor de pressão e a saída era amplificada, } \\
\text { gravada, convertida para valores de força e mostrada em um } \\
\text { computador. A superfície do tubo possuía sete marcas destinadas ao } \\
\text { posicionamento dos incisivos centrais. Tais marcas encontravam-se } \\
\text { entre } 0,5 \text { e } 3,5 \mathrm{~cm} \text { de distância da extremidade do tubo que continha } \\
\text { o balão e possuíam } 0,5 \mathrm{~cm} \text { de incremento. Dessa maneira, a força de } \\
\text { protrusão do músculo genioglosso podia ser medida em diferentes } \\
\text { comprimentos dependendo do local onde se posicionava os dentes. }\end{array}$ & $\begin{array}{l}11 \text { homens } \\
\text { entre } 19 \text { e } 41 \\
\text { anos. }\end{array}$ & $\begin{array}{l}\text { Força máxima obtida: } \\
28,0 \pm 2,0 \mathrm{~N} \text {. A maioria } \\
\text { dos sujeitos obteve } \\
\text { força máxima de língua } \\
\text { quando o transdutor } \\
\text { estava na posição de } \\
2,5 \mathrm{~cm} \text {. }\end{array}$ \\
\hline $\begin{array}{c}\text { Hayashi et al., } \\
20022^{22}\end{array}$ & $\begin{array}{l}\text { Instrumento que empregou um bulbo feito de borracha, preenchido } \\
\text { por ar, conectado por um tubo a um transdutor de pressão, um } \\
\text { amplificador e um sistema de gravação dos dados para avaliação da } \\
\text { pressão exercida pela língua. }\end{array}$ & $\begin{array}{c}41 \text { sujeitos } \\
\text { com idades } \\
\text { entre } 24 \text { e } 85 \\
\text { anos, sendo } 16 \\
\text { homens e } 25 \\
\text { mulheres }\end{array}$ & $\begin{array}{c}\text { Os valores obtidos } \\
\text { foram de } 10 \mathrm{kPa} \text { a } 41 \\
\mathrm{kPa} \text { com média de } 27 \\
\mathrm{kPa} \text {. }\end{array}$ \\
\hline
\end{tabular}




\begin{tabular}{|c|c|c|c|}
\hline $\begin{array}{l}\text { TECNOLOGIA/ } \\
\text { REFERÊNCIA }\end{array}$ & MÉTODO PROPOSTO & AMOSTRA & RESULTADOS \\
\hline $\begin{array}{l}\text { Clark et al., } \\
2003^{2}\end{array}$ & $\begin{array}{l}\text { O lowa Oral Pressure Instrument (IOPI) é a segunda versão do } \\
\text { aparelho proposto por Robin et al., 1992. A diferença é que o bulbo } \\
\text { do IOPI é preenchido com ar. O IOPI é comercialmente disponível e } \\
\text { foi utilizado por muitos autores na investigação da pressão da língua. } \\
\text { O IOPI apresenta um suporte para medir pressão de lateralização e } \\
\text { protrusão de língua. }\end{array}$ & $\begin{array}{l}63 \text { sujeitos de } \\
19 \text { a } 95 \text { anos, } \\
\text { sendo } 28 \\
\text { homens e } 35 \\
\text { mulheres }\end{array}$ & $\begin{array}{c}\text { Os sujeitos } \\
\text { classificados como } \\
\text { tendo força normal } \\
\text { de língua alcançaram } \\
\text { valores de pressão } \\
\text { máxima de } 40 \mathrm{kPa} \text { e } \\
\text { força média de } 35 \mathrm{kPa} \text {. }\end{array}$ \\
\hline $\begin{array}{l}\text { McAuliffe et al., } \\
200523\end{array}$ & $\begin{array}{l}\text { Instrumento semelhante ao utilizado em outro estudo da literatura } \\
22 \text {, sendo composto por um bulbo de borracha preenchido por ar } \\
\text { conectado a um transdutor de pressão, por meio de um cilindro de } \\
\text { plástico, para medir a pressão da língua contra o palato. }\end{array}$ & $\begin{array}{l}15 \text { sujeitos de } \\
20 \text { a } 31 \text { anos, } \\
\text { sendo nove } \\
\text { homens e seis } \\
\text { mulheres. }\end{array}$ & $\begin{array}{l}\text { Valores médios de } \\
36,92 \pm 6,44 \mathrm{kPa} \text {. }\end{array}$ \\
\hline Ball et al., $2006^{24}$ & $\begin{array}{l}\text { Descreveram um instrumento integrado à Kay Swallowing } \\
\text { Workstation para mensuração da pressão lingual, sendo esse } \\
\text { composto por um arranjo de três bulbos de silicone ligados entre si, } \\
\text { integrados a um sistema computacional capaz de coletar a pressão } \\
\text { exercida pela língua em três pontos do palato simultaneamente. }\end{array}$ & $\begin{array}{l}21 \text { sujeitos, } \\
\text { sendo } 15 \\
\text { homens e seis } \\
\text { mulheres, com } \\
\text { média de idade } \\
\text { de } 63,6 \text { anos. }\end{array}$ & $\begin{array}{l}\text { Pressão durante a } \\
\text { deglutição entre } \\
7,76 \text { e } 20,56 \mathrm{kPa} \text {. }\end{array}$ \\
\hline $\begin{array}{c}\text { Utanohara et al., } \\
200825\end{array}$ & $\begin{array}{l}\text { Aparelho para medir pressão de língua composto por uma sonda } \\
\text { descartável, um tubo de infusão como conector e um dispositivo } \\
\text { gravador. A sonda foi montada com um bulbo pequeno, parcialmente } \\
\text { inflado, feito de látex cirúrgico, um cano plástico como conector } \\
\text { e um cilindro de seringa para o paciente segurar. Foi utilizado } \\
\text { um dispositivo gravador com um sistema de auto-pressurização } \\
\text { manual. Quando o botão de pressurização era acionado, a sonda } \\
\text { era inflada com ar, a uma pressão inicial de } 19,6 \mathrm{kPa} \text {. Esta pressão } \\
\text { foi estabelecida como padrão e as medidas foram realizadas após } \\
\text { a calibração do zero. Os sujeitos foram solicitados a posicionar o } \\
\text { bulbo na boca, segurando o cano plástico pelo meio com os incisivos } \\
\text { centrais com os lábios ocluídos, levantar a língua e comprimir o } \\
\text { bulbo contra o palato com a maior força possível, tendo-se gravado } \\
\text { o valor máximo obtido. }\end{array}$ & $\begin{array}{l}843 \text { sujeitos, } \\
\text { sendo } 408 \\
\text { homens e } 445 \\
\text { mulheres, entre } \\
20 \text { e } 79 \text { anos. }\end{array}$ & $\begin{array}{c}\text { A média das forças } \\
\text { máximas foi de } \\
41,7 \pm 9,7 \mathrm{kPa} \text { em } \\
\text { sujeitos de } 20 \text { a } 29 \\
\text { anos; } 41,9 \pm 9,9 \mathrm{kPa}(30 \\
\text { a } 39 \text { anos); } 40,4 \pm 9,8 \\
\mathrm{kPa}(40 \text { a } 49 \text { anos); } \\
40,7 \pm 9,8 \mathrm{kPa}(50 \mathrm{a} \\
59 \text { anos); } 37,6 \pm 8,8 \\
\mathrm{kPa}(60 \text { a } 69 \text { anos); e } \\
31,9 \pm 8,9 \mathrm{kPa}(70 \text { a } 79 \\
\text { anos). }\end{array}$ \\
\hline
\end{tabular}

Figura 3 - dispositivos que empregam bulbos preenchidos com fluidos conectados a sensores de pressão

\begin{tabular}{|c|c|c|c|}
\hline $\begin{array}{l}\text { TECNOLOGIA/ } \\
\text { REFERÊNCIA }\end{array}$ & MÉTODO PROPOSTO & AMOSTRA & RESULTADOS \\
\hline Rumburg, $1986^{26}$ & $\begin{array}{l}\text { Aparelho baseado em um dinamômetro que consistia em uma base } \\
\text { que fornecia suporte a uma haste na qual havia uma espátula na } \\
\text { posição vertical. Esta espátula era o local onde os sujeitos exerciam } \\
\text { a força protruindo a língua. O deslocamento horizontal da espátula } \\
\text { movia a mola e a força exercida era mostrada em um micrômetro } \\
\text { por meio de uma escala criada pelo inventor. O aparelho também } \\
\text { possuía um apoio para o queixo, que determinava o posicionamento } \\
\text { do paciente em relação ao instrumento. }\end{array}$ & $x$ & $x$ \\
\hline $\begin{array}{c}\text { Price, Darvell, } \\
1981^{27}\end{array}$ & $\begin{array}{l}\text { Um aparelho para medição da pressão exercida pela língua baseado } \\
\text { na tarefa de sucção foi construído partindo do princípio de que, } \\
\text { durante a sucção, a pressão intra-oral negativa é gerada ativamente } \\
\text { pela língua, tendo as outras estruturas orais (bochechas, lábios } \\
\text { e palato mole) um papel passivo. O aparelho intra-oral removível } \\
\text { compreendia um canudo constituído por um cilindro retirado de uma } \\
\text { seringa plástica descartável de } 2,5 \mathrm{~mL} \text { dentro do qual um pedaço } \\
\text { de algodão foi inserido para contenção da saliva. Ao tubo foi ligado } \\
\text { um medidor de pressão do tipo Bourdon. A extremidade livre do } \\
\text { tubo foi comprimida aquecendo-se e pressionando o tubo para } \\
\text { prender o pedaço de algodão para prevenir a aspiração acidental do } \\
\text { algodão. Durante as medições o indivíduo sugava o canudo o mais } \\
\text { forte possível. A redução na pressão dentro do tubo era gravada e } \\
\text { interpretada pelos autores como indicativo da força da língua. }\end{array}$ & $\begin{array}{l}139 \text { sujeitos, } \\
\text { divididos em } \\
\text { três grupos: } \\
11 \text { idosos } \\
\text { com dentes; } \\
95 \text { idosos } \\
\text { edêntulos e } \\
33 \text { jovens com } \\
\text { dentes. }\end{array}$ & $\begin{array}{l}\text { Pressão máxima: em } \\
\text { idosos com dentes, } \\
263,2 \mathrm{mmHg} \text {, em } \\
\text { idosos edêntulos, 297,1 } \\
\text { mmHg, e em jovens } \\
\text { com dentes, } 276,7 \\
\text { mmHg. Houve uma } \\
\text { diminuição da força de } \\
\text { sucção com o avanço } \\
\text { da idade. }\end{array}$ \\
\hline
\end{tabular}




\begin{tabular}{|c|c|c|c|}
\hline $\begin{array}{l}\text { TECNOLOGIA/ } \\
\text { REFERÊNCIA }\end{array}$ & MÉTODO PROPOSTO & AMOSTRA & RESULTADOS \\
\hline $\begin{array}{l}\text { Frolich et al., } \\
1990^{28}\end{array}$ & $\begin{array}{l}\text { Instrumento que se caracteriza por uma cânula aberta, embutida em } \\
\text { molde de acrílico personalizado e fixada aos dentes para medir a } \\
\text { pressão da língua sobre os dentes. A cânula projetava-se de } 2 \text { a } 3 \\
\text { mm da superfície lingual do dente. A extremidade aberta da cânula } \\
\text { encontrava-se voltada para o interior da cavidade oral podendo } \\
\text { ser tocada pela língua, e o corpo da cânula passava ao longo da } \\
\text { superfície lingual dos dentes, curvando-se próximo ao dente mais } \\
\text { distal da arcada dentária e retornando ao longo da superfície } \\
\text { bucal dos dentes posteriores. A cânula era conectada a um tubo } \\
\text { que passava pela comissura labial terminado em um sistema } \\
\text { de medição de pressão extraoral. Este sistema consistia de um } \\
\text { recipiente contendo água e ar comprimido, um transdutor de pressão } \\
\text { e uma válvula de controle de fluxo. A pressão ocasionava o escape } \\
\text { de um fluxo contínuo de água } 2 \text { mL/min, pela extremidade aberta } \\
\text { da cânula. Quando esta extremidade era tocada pela língua, uma } \\
\text { resistência ao escape da água era gerada. A pressão da água era } \\
\text { medida e gravada pelo transdutor. Tal pressão refletia a pressão da } \\
\text { língua sobre a cânula. A água que fluía da cânula era deglutida pelo } \\
\text { participante. As medições foram realizadas na posição habitual de } \\
\text { língua, durante a mastigação e deglutição de água. }\end{array}$ & $\begin{array}{c}25 \text { sujeitos } \\
\text { sendo } 23 \\
\text { homens e } 2 \\
\text { mulheres com } \\
\text { idades entre } \\
22 \text { e } 33 \text { anos e } \\
\text { oclusão normal. }\end{array}$ & $\begin{array}{c}\text { A pressão média } \\
\text { exercida pela língua } \\
\text { durante a posição } \\
\text { habitual foi de }-0,17 \\
\mathrm{kPa} \text { no incisivo } \\
\text { superior, }-0,001 \mathrm{kPa} \text { no } \\
\text { incisivo inferior, }-0,03 \\
\mathrm{kPa} \text { no molar superior } \\
\text { e } 0,48 \mathrm{kPa} \text { no molar } \\
\text { inferior. } \mathrm{Na} \text { tarefa de } \\
\text { mastigação a língua } \\
\text { exerceu pressões de } \\
5,08 \mathrm{kPa}, 9,41 \mathrm{kPa}, \\
9,34 \mathrm{kPa} \text { e } 14,33 \mathrm{kPa} \\
\text { e na deglutição as } \\
\text { pressões foram de } \\
19,65 \mathrm{kPa}, 32,65 \mathrm{kPa} \text {, } \\
30,45 \mathrm{kPa} \text { e } 27,56 \mathrm{kPa} \\
\text { no incisivo superior, } \\
\text { incisivo inferior, molar } \\
\text { superior e molar inferior } \\
\text { respectivamente. }\end{array}$ \\
\hline $\begin{array}{c}\text { Motta et al., } \\
200429\end{array}$ & $\begin{array}{l}\text { Instrumento desenvolvido para a medição das forças axiais } \\
\text { produzidas pela língua. Tal método é baseado na transformação da } \\
\text { força em pressão e sua posterior reconversão em força e consistia de } \\
\text { um conjunto pistão-cilindro com um protetor oral duplo, de silicone, } \\
\text { acoplado hidraulicamente a um transdutor de pressão. O conjunto } \\
\text { pistão-cilindro foi acoplado à boca dos indivíduos e, após um período } \\
\text { de acomodação de aproximadamente } 15 \text { segundos, foi solicitado aos } \\
\text { indivíduos que impulsionassem o êmbolo com a maior força de que } \\
\text { fossem capazes de realizar e manter por } 10 \text { segundos. Os valores } \\
\text { de força foram registrados à frequência de } 4,5 \mathrm{~Hz} \text {. O procedimento } \\
\text { foi realizado por mais duas vezes com intervalos de dois minutos de } \\
\text { descanso entre as medições. Os parâmetros analisados foram: força } \\
\text { máxima, referindo-se ao valor máximo obtido no primeiro pico de } \\
\text { força; força média; taxa média de aplicação inicial, que caracteriza a } \\
\text { velocidade com a qual a força atinge o primeiro pico e a área sob a } \\
\text { curva, que é a medida da energia dissipada pela língua. }\end{array}$ & $\begin{array}{c}\text { Quatro sujeitos, } \\
\text { sendo dois } \\
\text { homens com } \\
\text { idades de } 23 \text { e } \\
29 \text { anos e duas } \\
\text { mulheres de } 32 \\
\text { e } 31 \text { anos. }\end{array}$ & $\begin{array}{l}\text { Força máxima } 25,7 \mathrm{~N} ; \\
21,7 \mathrm{~N} ; 21,6 \mathrm{~N} ; \text { e } 21,1 \\
\mathrm{~N} . \text { Força média: } 20,6 \\
\mathrm{~N} ; 18,2 \mathrm{~N} ; 17,4 \mathrm{~N} ; \mathrm{e} \\
18,6 \mathrm{~N} \text {. Taxa média de } \\
\text { aplicação inicial: } 24,3 \\
\mathrm{~N} / \mathrm{s} ; 19,3 \mathrm{~N} / \mathrm{s} ; 10,8 \\
\mathrm{~N} / \mathrm{s} ; \text { e } 10,3 \mathrm{~N} / \mathrm{s} . \text { Área } \\
\text { sob a curva: } 203 \mathrm{~J} / \mathrm{N} . \mathrm{s} ; \\
186 \mathrm{~J} / \mathrm{N} . \mathrm{s} ; 164 \mathrm{~J} / \mathrm{N} . \mathrm{s} ; \\
\text { e } 180 \mathrm{~J} / \mathrm{N} . \mathrm{s} \text {. Os dados } \\
\text { se referem ao homem } \\
\text { de } 23 \text { anos, o de } 29 \\
\text { anos, a mulher de } 32 \\
\text { anos e a de } 31 \text { anos, } \\
\text { respectivamente. }\end{array}$ \\
\hline $\begin{array}{l}\text { O'Connor et al., } \\
2007^{30}\end{array}$ & $\begin{array}{l}\text { A força de protrusão da língua foi medida utilizando um transdutor de } \\
\text { força (Grass FT10 Force Displacement Transducer) preso em uma } \\
\text { estrutura vertical. O instrumento possuía uma peça a ser alojada } \\
\text { na cavidade oral. Tal peça tinha uma almofada para posicionamento } \\
\text { dos dentes. Os indivíduos mordiam a almofada e pressionavam a } \\
\text { língua contra um botão circular de } 20 \mathrm{~mm} \text { de diâmetro conectado } \\
\text { ao transdutor de força por meio de uma viga cilíndrica de aço de } 5 \\
\mathrm{~mm} \text { de diâmetro e } 50 \mathrm{~mm} \text { de comprimento. O botão projetava-se } \\
25 \mathrm{~mm} \text { da almofada de posicionamento dos dentes para dentro da } \\
\text { cavidade oral. Foi medida a força máxima de protrusão na contração } \\
\text { voluntária por um período de } 5 \text { segundos. A porcentagem de força } \\
\text { em relação à força máxima era mostrada em um osciloscópio para } \\
\text { fornecer feedback visual. }\end{array}$ & $\begin{array}{c}12 \text { sujeitos do } \\
\text { sexo masculino } \\
\text { com média de } \\
\text { idade de } 23 \\
\text { anos. }\end{array}$ & $\begin{array}{l}\text { Força máxima: } \\
24,3 \pm 6,7 \mathrm{~N} \text {. }\end{array}$ \\
\hline $\begin{array}{l}\text { Lambrechts et al., } \\
\qquad 2010^{31}\end{array}$ & $\begin{array}{l}\text { O Myometer } 160 \text {, desenvolvido para medir pressão ou tensão } \\
\text { da língua, consistia de duas placas retangulares dispostas } \\
\text { paralelamente uma em relação à outra e aparafusadas entre si em } \\
\text { uma das suas extremidades. Na outra extremidade encontravam se } \\
\text { livres e podiam ser empurradas, uma em direção à outra. A força } \\
\text { aplicada era medida por um aparato eletrônico, não detalhado no } \\
\text { estudo, instalado entre as placas e era mostrada no aparelho por } \\
\text { meio de um visor em gráfico de barras. Para as medições da força da } \\
\text { língua uma peça era parafusada na sonda. O paciente posicionava } \\
\text { os lábios em torno da abertura da referida peça e protruía a língua } \\
\text { exercendo a maior força que conseguisse na extremidade livre da } \\
\text { placa da sonda. }\end{array}$ & $\begin{array}{c}107 \text { sujeitos, } \\
\text { sendo } 63 \\
\text { mulheres e } 44 \\
\text { homens entre } \\
7 \text { e } 45 \text { anos de } \\
\text { idade. }\end{array}$ & $\begin{array}{l}\text { Força média: } 1,66 \pm 0,06 \\
\text { N. Não foi observada } \\
\text { relação significante } \\
\text { entre força de língua } \\
\text { e sexo, idade, } \\
\text { características da } \\
\text { oclusão dentária ou } \\
\text { presença de hábitos } \\
\text { orais deletérios. }\end{array}$ \\
\hline
\end{tabular}




\begin{tabular}{|c|c|c|c|}
\hline $\begin{array}{l}\text { TECNOLOGIA/ } \\
\text { REFERÊNCIA }\end{array}$ & MÉTODO PROPOSTO & AMOSTRA & RESULTADOS \\
\hline $\begin{array}{l}\text { Reilman et al., } \\
2010^{32}\end{array}$ & $\begin{array}{l}\text { Transdutor de força composto por um sensor da marca ATI } \\
\text { Industrial Automation, modelo Mini- } 40 \text {, fixado sobre uma superfície } \\
\text { circular plana de } 40 \mathrm{~mm} \text { de diâmetro, posicionada a } 2 \mathrm{~cm} \text { da boca } \\
\text { do indivíduo e coberto por uma capa plástica; um suporte para } \\
\text { posicionamento do queixo sobre uma base de altura regulável; e um } \\
\text { monitor posicionado } 30 \mathrm{~cm} \text { na frente do sujeito para apresentação } \\
\text { de feedback visual da força exercida pela língua. Os indivíduos } \\
\text { deveriam manter a força em um nível predeterminado de } 0,25,0,5 \\
\text { ou } 1 \mathrm{~N} \text {. }\end{array}$ & $\begin{array}{l}20 \text { indivíduos } \\
\text { normais, sendo } \\
12 \text { mulheres e } \\
8 \text { homens com } \\
\text { idades entre } 20 \\
\text { e } 63 \text { anos. }\end{array}$ & $\begin{array}{c}\text { Apenas a variabilidade } \\
\text { dos dados foi } \\
\text { analisada. }\end{array}$ \\
\hline $\begin{array}{c}\text { Trawitzki et al., } \\
2011^{33}\end{array}$ & $\begin{array}{l}\text { Dinamômetro digital contendo duas hastes com discos de teflon nas } \\
\text { extremidades onde a força era aplicada na direção vertical. Medições } \\
\text { eram obtidas usando uma célula de carga e um circuito eletrônico e } \\
\text { os valores de força eram fornecidos em um visor digital. A força foi } \\
\text { avaliada na porção anterior e no dorso da língua. }\end{array}$ & $\begin{array}{l}50 \text { indivíduos } \\
\text { saudáveis, } \\
\text { sendo } 17 \\
\text { homens e } 33 \\
\text { mulheres, de } 18 \\
\text { a } 37 \text { anos }\end{array}$ & $\begin{array}{l}\text { A força máxima foi de } \\
\text { aproximadamente } 1,1 \\
\text { gf para os homens e } \\
0,7 \text { gf para as mulheres } \\
\text { na região anterior da } \\
\text { língua e de } 1,5 \text { gf e } \\
1,1 \text { gf para o dorso, } \\
\text { respectivamente. } \\
\text { Verificou-se diferença } \\
\text { significante entre } \\
\text { os sexos e entre as } \\
\text { regiões da língua. }\end{array}$ \\
\hline
\end{tabular}

Figura 4 - dispositivos que empregam outras tecnologias

Muitos pesquisadores desenvolveram métodos para quantificar força/pressão exercida pela língua utilizando diferentes tecnologias. Observou-se uma tendência dos primeiros instrumentos desenvolvidos a empregarem extensômetros. Recentemente, o número de pesquisadores que utilizaram bulbos e placas palatais com sensores de pressão aumentou. Cada categoria apresenta aspectos positivos e negativos.

Os instrumentos que utilizam extensômetros ${ }^{3-9}$ geralmente apresentam uma estrutura mecânica pesada, necessária para seu funcionamento e também possuem estruturas dos sensores pouco flexíveis, o que pode causar feridas ou desconforto ao paciente. Outro problema específico, já ocorrido na literatura ${ }^{3}$ é a falta de uma peça que faça a interface entre a língua e o transdutor, sendo então possível medir apenas a pressão de contato da língua e não a pressão total da língua.

Placas palatais ${ }^{12-14,16-18}$ precisam ser personalizadas, pois cada indivíduo tem um tamanho e formato de palato diferente. Além disso, só permitem a avaliação da força na direção cranial. Entretanto, são eficientes para medir força de língua durante as funções, já que permitem que o paciente feche a boca e desempenhe as funções quase normalmente. Outro método alternativo é fixar os sensores diretamente no palato ${ }^{19}$ ou nos dentes ${ }^{15}$. Este método apresenta duas desvantagens. A primeira é a dificuldade de se acomodar os sensores em um ponto estabelecido, para que seja possível a comparação com reavaliações, como por exemplo, antes e depois da terapia miofuncional orofacial. A segunda desvantagem é que os sensores são difíceis de serem desinfectados adequadamente $e$, por isso, não podem ser utilizados em diferentes pacientes. Entretanto, este método é melhor do que as placas palatais para medir força durante as funções, por ser menos espesso.

O problema dos bulbos ${ }^{2,20-25}$ é a dificuldade na reprodutibilidade do posicionamento na cavidade oral. Bulbos preenchidos por ar são difíceis de serem ajustados devido a estes escorregarem facilmente na superfície da língua e o tubo conector não ter marcações para indicar a posição do mesmo depois do fechamento dos lábios. Além disso, este tipo de instrumento deveria conter um sistema de pressurização como proposto na literatura ${ }^{25}$, para manter o bulbo inflado com ar à mesma pressão antes de cada medição.

Alguns instrumentos apresentaram características específicas que não permitiram o agrupamento em nenhuma das categorias definidas ${ }^{26-33}$. Observa-se também instrumentos com utilização restrita em pacientes com dificuldade de deglutição, devido ao risco de aspiração de água ${ }^{28}$. A desvantagem de se utilizar dinamômetros ${ }^{26,33}$ é que eles não são tão sensíveis a pequenas mudanças de força e, em alguns casos, as medidas não são tão confiáveis, já que a força pode ter sido gerada pelo sujeito, ou pela mão do avaliador em direção à boca do paciente e não necessariamente pela língua.

O aparelho criado pelo Grupo de Engenharia Biomecânica da Universidade Federal de Minas 
Gerais ${ }^{29}$, denominado FORLING, é o primeiro instrumento de medição de força de língua desenvolvido no Brasil. A principal limitação deste foi a dificuldade no desenvolvimento de um atuador com baixo atrito e isento de vazamentos. Devido aos vazamentos, a água contida no interior do aparelho tinha que ser completada após cada medição, o que tornava o procedimento trabalhoso. $O$ instrumento também era grande, o que dificultava o transporte. Além disso, alguns componentes eram de vidro, o que fazia com que o sistema se tornasse mais frágil, com consequente risco de quebra. $\mathrm{E}$ finalmente, o sensor era capaz de medir forças de 0 a $40 \mathrm{~N}$ e alguns pacientes conseguiram exercer forças maiores em tarefas de protrusão, o que gerava saturação do sistema. O sistema já foi aperfeiçoado ${ }^{11}$ e encontra-se em fase de testes.

Em geral, a maior parte dos instrumentos mede força de língua em apenas uma direção. Contudo, a atividade lingual durante as funções envolve uma combinação de forças estáticas e dinâmicas, já que a língua é orientada em diferentes posições. As medições geralmente ocorrem enquanto o indivíduo está desempenhando uma tarefa voluntária, o que requer um nível alto de cognição, enquanto que as funções são mais instintivas do que cognitivas, e podem ser coordenadas em diferentes níveis cerebrais ${ }^{5}$. Alguns instrumentos, por apresentarem tamanho grande, são difíceis de serem transportados ${ }^{9,29}$ e a falta de reprodutibilidade no posicionamento do sensor dentro da cavidade oral dificulta comparações com avaliações subsequentes.

A grande variação de valores de força e de pressão máxima e média encontrados relaciona-se à grande diversidade dos aparelhos, que empregam diferentes tecnologias. Diferenças metodológicas dificultam a comparação entre os estudos, já que os valores dependem de um número grande de fatores, como grau de protrusão da língua, direção do movimento, distância entre mandíbula e maxila, região da língua em contato com o sensor e área na qual a pressão é exercida. A falta de reprodutibilidade em algum destes parâmetros pode levar à variação significante nos resultados obtidos ${ }^{5}$.

Alguns trabalhos descreveram o uso da eletromiografia para estimar a força muscular ${ }^{34}$, já que a amplitude do sinal eletromiográfico normalmente cresce à medida que a força muscular aumenta, promovendo uma indicação qualitativa da relação entre estas variáveis. Tanto eletrodos intraorais não-invasivos 6,7, como eletrodos intramusculares ${ }^{35,36}$ foram utilizados na língua. Eletrodos de superfície apresentam algumas vantagens em relação aos intramusculares, pois os primeiros são mais fáceis de utilizar e apresentam maior aceitação por parte dos pacientes. Entretanto, para medir a atividade eletromiográfica da musculatura intrínseca da língua, são necessários eletrodos intramusculares ${ }^{37}$.

O uso de métodos quantitativos para medir força de língua ajuda o profissional na avaliação de motricidade orofacial, principalmente nos sujeitos com diminuição de força discreta, que é difícil de ser notada na avaliação clínica. Outra vantagem da avaliação quantitativa é a possibilidade de acompanhar a evolução da terapia e facilitar a comunicação entre os profissionais envolvidos no tratamento dos pacientes, melhorando a compreensão durante a discussão de casos clínicos. O prognóstico do tratamento pode ser definido com mais precisão se baseado nos valores de força obtidos. Assim, a avaliação quantitativa tem um importante papel como instrumento complementar de análise, em associação à avaliação qualitativa, já que a experiência profissional é fundamental para se perceber as reais necessidades do paciente.

\section{CONCLUSÃO}

Foram encontrados diversos métodos de avaliação instrumental da língua, sendo que a grande maioria dos trabalhos apresentou seus resultados de força, em newtons, e de pressão, em quilopascal, de forma proporcional entre os dois parâmetros. Todos os métodos podem, potencialmente, auxiliar o profissional na avaliação miofuncional orofacial, fazendo com que o diagnóstico de força da língua seja mais preciso. De acordo com o modelo de cada aparelho, pode-se considerar que cada um seja mais indicado para um tipo de avaliação da força lingual, já que vários músculos estão envolvidos na movimentação desse órgão. 


\begin{abstract}
For several years, researchers have been looking for methods to quantify tongue force and a lot of devices were constructed for this purpose. The purpose of this study is to present a critical literature review about the devices to quantify tongue strength. Thirty devices were found. They were grouped into four different categories: mouthpiece containing sensors $(n=9)$, sensors attached on teeth surface or on palatal plates $(n=8)$, bulbs filled with some fluid and connected to a pressure sensor $(n=7)$ and other technologies $(n=8)$. These methods can, potentially, help speech-language pathologists in the orofacial myology evaluation, making the diagnosis of tongue force more reliable. Some of them present disadvantages such as not being sensitive enough to small changes in force, difficulties in positioning reproducibility and other specific points. The large variation in maximum and average strength/pressure values are related to the large diversity of the methods, which use different technologies.
\end{abstract}

KEYWORDS: Tongue; Muscle Strength; Evaluation

\section{REFERÊNCIAS}

1. Proffit WR, Fields Jr HW. A etiologia dos problemas ortodônticos. In: Ortodontia Contemporânea. $3^{\text {a }}$ ed. Rio de Janeiro: Guanabara Koogan; 2002. P.105-34.

2. Clark HM, Henson PA, Barber WD, Stierwalt JAG, Sherrill M. Relationships among subjective and objective measures of the tongue strength and oral phase swallowing impairments. Am J Speech Lang Pathol. 2003;12:40-50.

3. Dworkin JP, Aronson AE, Mulder DW. Tongue force in normals and dysarthric patients with amyotrophic lateral sclerosis. J Speech Hear Res. 1980;23(4):828-37.

4. Durkee DL, Manning FE, inventors; Durkee DL, Manning FE, assignee. Tongue force measuring device. US patent 4.697.601. 1987 Oct 6 .

5. Robinovitch SN, Hershler C, Romilly DP. A tongue force measurement system for the assessment of oral-phase swallowing disorders. Arch Phys Med Rehabil. 1991;72:38-42.

6. Scardella AT, Krawciw N, Petrozzino JJ, Co MA, Santiago TV, Edelman NH. Strength and endurance characteristics of the normal human genioglossus. Am Rev Respir Dis. 1993;148:179-84.

7. Blumen MB, de La Sota AP, Quera-Salva MA, Frachet B, Chabolle F, Lofaso F. Genioglossal electromyogram during untington contraction in normal humans. Eur $\mathrm{J}$ Appl Physiol. 2002;88(1-2):170-7.

8. Mortimore IL, Fiddes P, Stephens S, Douglas NJ. Tongue protrusion force and fatiguability in male and female subjects. J Sleep Res. 1999;14:191-5.

9. Miller BD, Pehlman-Wilkin D, inventors; Miller BD, Pehlman-Wilkin D, assignee. Apparatus and method for measurement of force exerted by the tongue and the lips and their applications in tests and therapies. US patent 0.183.107. $2008 \mathrm{Jul} 31$. 10. Sangave A, Manuccia T, Kay Matthew, Zderic Vesna. Lingual force detection system. Conf Proc IEEE Eng Med Biol Soc. 2008;2008:4844-7.

11. Furlan RMMM. Desenvolvimento de um aparelho portátil para quantificação e reabilitação da força da língua [dissertação]. Belo Horizonte (MG): Universidade Federal de Minas Gerais. Departamento de Engenharia Mecânica; 2011.

12. Staehlin JH, Light J, O'Reilly W, Buck D, Knight J, Robinson M, et al., inventors; Volunteers for Medical Engineering, assignee. Method and apparatus for oral motor therapy using a visual display. US patent 5.954.673. 1999 Sept 21.

13. Wakumoto M, Masaki S, Ooue T, inventors; Advanced Telecommunications Research Institute International, assignee. System for measure tongue pressure. US patent US 6.511.441. 2003 Jan 28.

14. Robbins J, Bomsztyk ED, Heppner AL, Koranda $\mathrm{CL}$, Kroner AR, Kuchenreuther JM, et al., inventors; Apparatus for measuring tongue/hard palate contact pressure. US patent 6.702.7665 B2. 2004 Mar 9.

15. Ruan W, Chen M, Gu Z, Lu Y, Su J, Guo Q. Muscular forces exerted on the normal deciduous dentition. Angle Orthod. 2005;75(5):785-90.

16. Hori K, Ono T, Nokubi T. Coordination of tongue pressure and jaw movement in mastication. J Dent Res. 2006;85(2):187-91.

17. Hewitt A, Hind J, Kays S, Nicosia M, Doyle J, Tompkins $W$ et al. Standardized instrument for lingual pressure measurement. Dysphagia. 2008;23(1):16-25.

18. Kieser J, Singh B, Swain M, Ichim I, Waddell JN, Kennedy D et al. Measuring intraoral pressure: 
adaptation of a dental appliance allows measurement during function. Dysphagia. 2008;23:237-43.

19. Hori K, Ono T, Tamine K, Kondo J, Hamanaka $S$, Maeda $Y$ et al. Newly developed sensor sheet for measuring tongue pressure during swallowing. J Prosthodont Res. 2009;53:28-32.

20. Robin DA, Lushei ES, inventors; University of lowa Research Foundation, assignee. System and method for detecting pressure of selected body parts. US patent 5.119.831. 1992 Jun 9.

21. Bu Sha BF, England SJ, Parisi RA, Strobel RJ. Force production of the genioglossus as a function of muscle length in normal humans. J Appl Physiol. 2000;88:1678-84.

22. Hayashi R, Tsuga K, Hosokawa R, Yoshida $\mathrm{M}$, Sato $\mathrm{Y}$, Akagawa $\mathrm{Y}$. A novel handy probe for tongue pressure measurement. Int $\mathrm{J}$ Prosthodont. 2002;15(4):385-8.

23. McAuliffe MJ, Ward EC, Murdoch BE, Farrell AM. A nonspeech investigation of tongue function in Parkinson's disease. J Gerontol A Biol Sci Med Sci. 2005;60(5):667-74.

24. Ball S, Idel O, Cotton S, Perry A. Comparison of two methods for measuring tongue pressure during swallowing in people with head and neck cancer. Dysphagia. 2006;21(1):28-37.

25. Utanohara $Y$, Hayashi $R$, Yoshikawa $M$, Yoshida M, Tsuga K, Akagawa Y. Standard values of maximum tongue pressure taken using newly developed disposable tongue pressure measurement device. Dysphagia. 2008;23:286-90.

26. Rumburg LK, inventor; Rumburg LK, assignee. Tongue musculature measurement and strengthening apparatus. US patent 4.585.012. 1986 Apr 29.

27. Price $P$, Darvell $B$. Force and mobility in the ageing human tongue. The Med J Aust. 1981;1:75-8. 28. Frohlich K, Thuer U, Ingervall B. Pressure from the tongue on the teeth in young adults. Angle Orthod.1990;61:17-24.

http://dx.doi.org/10.1590/S1516-18462012005000099

RECEBIDO EM: 04/11/2011

ACEITO EM: 29/02/2011

Endereço para correspondência:

Renata Maria Moreira Moraes Furlan

Laboratório MecBio. Avenida Antônio Carlos, 6627

Escola de Engenharia, Bloco I, sala 4205

Belo Horizonte - MG

CEP: 31210-000

E-mail: renatamfurlan@yahoo.com.br
29. Motta AR, Perim JV, Perilo TVC, Las Casas EB, Costa CG, Magalhães FE et al. Método objetivo para a medição de forças axiais da língua. Rev CEFAC. 2004;6:164-9.

30. O'Connor CM, Lowery MM, Doherty LS, McHugh M, O'Muircheartaigh C, Cullen $\mathrm{J}$ et al. Improved surface EMG electrode for measuring genioglossus muscle activity. Respir Physiol Neurobiol. 2007;159:55-67.

31. Lambrechts H, De Baets E, Fieuws S, Willems G. Lip and tongue pressure in orthodontic patients. Eur J Orthod. 2010;32(4):466-71.

32. Reilmann R, Bohlen S, Klopstock T, Bender A, Weindl A, Saemann $P$ et al. Tongue force analysis assesses motor phenotype in premanifest and symptomatic Huntington's disease. Mov Disord. 2010;25(13):2195-202.

33. Trawitzki LV, Borges CG, Giglio LD, Silva JB. Tongue strength of healthy young adults. J Oral Rehabil. 2011;38(7):482-6.

34. Staudenmann D, Daffertshofer A, Kingma I, Stegeman DF, Van Dieen JH. Independent component analysis of high-density electromyography in muscle force estimation. IEEE Trans Biomed Eng. 2007;54(4):751-4.

35. Hiyama $S$, Iwamoto $S$, Ono $T$, Ishiwata $Y$, Kuroda T. Genioglossus muscle activity during rhythmic open-close jaw movements. J Oral Rehabil. 2000;27:664-70.

36. Eastwood PR, Allison GT, Shepherd KL, Szollosi I, Hillman DR. Heterogeneous activity of the human genioglossus muscle assessed by multiple bipolar fine-wire electrodes. J Appl Physiol. 2003;94:1849-58.

37. Pittman LJ, Bailey EF. Genioglossus and intrinsic electromyographic activities in impeded and unimpeded protrusion tasks. J Neurophysiol. 2009;101(1):276-82. 